\title{
Penilaian Keterampilan Bertanya Calon Guru PAUD sebagai Strategi Pengembangan Kognitif Anak Usia Dini
}

\author{
Kartika Metafisika \\ STAI Taruna Surabaya \\ Email : kartikametafisika@gmail.com
}

\begin{tabular}{|c|c|}
\hline Kata Kunci: & Abstrak \\
\hline $\begin{array}{l}\text { Pendidikan } \\
\text { Anak Usia } \\
\text { Dini, } \\
\text { Pengembangan } \\
\text { Kognitif, } \\
\text { Keterampilan } \\
\text { Bertanya, } \\
\text { Keterampilan } \\
\text { Berpikir } \\
\text { Tingkat Tinggi }\end{array}$ & $\begin{array}{l}\text { Keterampilan bertanya adalah teknik yang penting untuk dikuasai oleh guru } \\
\text { Pendidkan Anak Usia Dini (PAUD) agar penalaran dan kemampuan pemecahan } \\
\text { masalah Anak Usia Dini (AUD) dapat berkembang maksimal. Dilakukan asesmen } \\
\text { terhadap keterampilan bertanya } 23 \text { calon guru PAUD mengacu pada kriteria level } \\
\text { pertanyaan Nielsen dengan metode analisis konten. diketahui bahwa sebanyak } 68 \% \\
\text { partisipan masih mengemukakan pertanyaan dalam bentuk Low Order Thinking } \\
\text { Skills (LOTS) dan } 32 \% \text { sudah mempraktekkan pertanyaan untuk mengembangkan } \\
\text { High Order Thinking Skills (HOTS). Semua partisipan memulai pertanyaan dari } \\
\text { pertanyaan deskripsi yakni tentang apa, siapa, dimana, dan kapan. Pertanyaan LOTS } \\
\text { yang muncul paling banyak seputar pertanyaan deskripsi mengenai apa, siapa, } \\
\text { dimana, dan kapan disertai berhitung jumlah objek. Pada pertanyaan HOTS, } \\
\text { pertanyaan yang ideal adalah pertanyaan yang melalui proses penalaran (Q3) atau } \\
\text { bagaimana anak bisa mengamati secara detail objek yang dipelajari melalui proses } \\
\text { membedakan (Q4). }\end{array}$ \\
\hline Keyv & Abstract \\
\hline $\begin{array}{l}\text { Early } \\
\text { Childhood } \\
\text { Education, } \\
\text { Cognitive } \\
\text { Development, } \\
\text { Questioning } \\
\text { Skills, High } \\
\text { Order } \\
\text { Thinking } \\
\text { Skills }\end{array}$ & $\begin{array}{l}\text { Questioning skills are an important technique to be mastered by Early Childhood } \\
\text { educators so that Early Childhood reasoning and problem solving skills can develop } \\
\text { optimally. An assessment of the questioning skills of } 23 \text { prospective Early Childhood } \\
\text { educators was conducted referring to the Nielsen question level criteria using the } \\
\text { content analysis method. It is known that as many as } 68 \% \text { of participants still raise } \\
\text { questions in the form of Low Order Thinking Skills (LOTS) and } 32 \% \text { have practiced } \\
\text { questions to develop High Order Thinking Skills (HOTS). All participants started the } \\
\text { question from the description question about what, who, where and when. The LOTS } \\
\text { questions that appear most revolve around description questions about what, who, } \\
\text { where, and when accompanied by counting the number of objects. In HOTS } \\
\text { questions, the ideal questions are questions that go through the process of reasoning } \\
\text { (Q3) or how children can observe in detail the objects learned through the process of } \\
\text { differentiating (Q4). }\end{array}$ \\
\hline
\end{tabular}

Submission: December 9, 2019. Revised: December 11, 2019. Accepted: December 12, 2019

\section{A. Pendahuluan}

Anak Usia Dini (AUD) saat ini merupakan generasi yang tumbuh di era teknologi informasi. Agar di masa depan anak dapat beradaptasi dengan perkembangan zaman, maka keterampilan untuk belajar terus menerus menjadi penting bagi anak didik sedari dini (Ting, 2007). Pengembangan keterampilan berpikir anak adalah pijakan yang perlu dikembangkan sejak dini agar anak siap untuk melanjutkan ke jenjang pendidikan selanjutnya (Welsh, Nix, Blair, Bierman, \& Nelson, 2010). Untuk mencapai tujuan tersebut, pemerintah sudah mengembangkan kurikulum 2013 yang pelaksanaannya mengacu pada pendekatan saintifik mulai dari Pendidikan Anak Usia Dini (PAUD) hingga Sekolah Menengah Atas (SMA).

Dalam pendekatan saintifik, anak diharapkan memiliki kemampuan untuk terlibat aktif dalam pembelajaran untuk bertanya, mengumpulkan informasi, bernalar, mengomunikasikan, 
dan mengamati. Permasalahan yang muncul adalah guru memiliki kesulitan dalam mengondisikan pendekatan saintifik (Danur \& Nurhafizah, 2019). Hal ini dapat disebabkan guru belum memiliki keterampilan memadai dalam menerapkan pembelajaran ideal dalam kelas (Natalia, Sofia, \& others, 2016), sedangkan keterampilan guru dalam menjelaskan materi sangat mempengaruhi hasil belajar dan kondisi psikologis siswa dalam belajar (Hartatik dan Fitriyah, 2017). Guru PAUD harus mendesain sendiri program pengembangan mulai dari perencanaan, pelaksanaan dan penilaian, berbeda dengan Kurikulum 2013 untuk Sekolah Dasar (SD) hingga SMA yang sudah dibimbing oleh pemerintah dalam melaksanakan kegiatan pembelajaran melalui buku panduan.

Langkah pertama dalam pelaksanaan pendekatan saintifik adalah mengasah keterampilan bertanya anak. Keterampilan bertanya adalah langkah penting dalam menstimulasi keterampilan bernalar (Storey, 2004) dan berpikir anak (Akkaya \& Demirel, 2012). Menurut Piaget, keterampilan berpikir tingkat tinggi perlu diciptakan untuk merestrukturisasi skema baru sesuai tahap perkembangan individu dan menciptakan disequilibrium (Storey, 2004). Program yang dikembangkan oleh (Aubrey, Ghent, \& Kanira, 2012) untuk melatih keterampilan berpikir siswa dengan pijakan teori perkembangan kognitif yang digagas oleh Piaget dan Vygotsky, menunjukkan bahwa pengembangan keterampilan bertanya dapat meningkatkan keterampilan berpikir kritis anak. Dalam kegiatannya, inisiasi guru dalam membentuk konflik kognitif menjadi bagian penting dari proses kegiatan pengembangan kognitif anak di PAUD.

Agar anak memiliki keterampilan bertanya, maka guru perlu memiliki keterampilan untuk memberikan verbalisasi yang dapat mengembangkan rasa ingin tahu anak dan tidak mengacu pada hafalan melainkan pada pemahaman (Katz, 2010). Berdasarkan hasil penelitian para ahli ditemukan bahwa pelatihan terhadap teknik bertanya secara sistematis pada guru dapat meningkatkan respon anak dibandingkan dengan pembelajaran dengan cara tradisional (Storey, 2004). Guru perlu merencanakan pertanyaan berdasarkan hierarki Taksonomi Bloom berawal dari keterampilan berpikir tingkat rendah (pengetahuan, pemahaman, aplikasi) menuju ke keterampilan berpikir tingkat tinggi (analisis, sintesis, evaluasi) (Storey, 2004).

Kesinambungan dalam memberikan pertanyaan dari keterampilan berpikir tingkat rendah ke tingkat tinggi adalah strategi penting mengingat anak usia dini. Hal tersebut dikarenakan anak memiliki keterbatasan kognitif (cognitive burden) yang akan membebani kognitif (Trundle, 2010) apabila stimulasi yang diberikan melebihi kapasitas berpikir anak sehingga guru perlu menentukan strategi scaffolding yang tepat agar pertanyaan-pertanyaan yang muncul sesuai tahap perkembangan berpikir anak. Berdasarkan level abstraksi Blank(Westby, 2017), pembelajaran akan efektif jika $70 \%$ kegiatan anak adalah hal yang dapat anak kuasai, dan $30 \%$ nya adalah hal yang perlu mereka pelajari dengan memperhatikan tingkatan abstraksi mereka secara gradual.

Strategi scaffolding bagi anak dapat dilakukan dengan mendesain rangkaian pertanyaan dan kegiatan seiring dengan level abstraksi anak. Marion Blank (Westby, 2017) telah memberikan pemikirannya mengenai tingkatan abstraksi pada anak yakni :

level 1: Persepsi Menyesuaikan. Pada persepsi ini anak menyocokkan pada apa yang ia lihat, sehingga pertanyaan yang cocok pada level ini adalah dengan memberi label, menunjukkan, dan mencocokkan. Level 2: analisis Selektif terhadap Persepsi. Pada perspektif ini anak diminta untuk menggambarkan secara detail mengenai objek yang ia ketahui. Sebagai contoh anak diminta untuk menceritakan apa yang ia ketahui tentang bagian-bagian sepeda. Level 3: Perspektif Penyusunan Kembali. Pada level ini anak diminta untuk menceritakan kembali apa yang ia lihat. Level 4: Perspektif Nalar. Pada level ini anak diminta untuk 
menjelaskan mengapa dan memprediksi sesuatu. Sebagai contoh guru meminta anak untuk memprediksi apa yang terjadi jika banyak sampah di sungai dan hujan turun sangat deras.

Meskipun Blank sudah memaparkan hierarki pertanyaan disertai contoh secara detail, pertanyaan yang berhubungan dengan penerapan berhitung tidak masuk ke dalam kriteria yang diajukan Blank sehingga peneliti menggunakan kriteria level pertanyaan yang dikembangkan oleh Nielsen, Buckingham, Knoll, Marsh, \& Palen (2008). Keunggulan dari kriteria yang dikembangkan oleh Nielsen et al adalah menggabungkan teori tipe pertanyaan Collins dengan Taksonomi Bloom sebagai acuan kriteria level pertanyaan sehingga ukuran pertanyaan yang mengacu pada LOTS dan HOTS Taksonomi Bloom sudah terwakili dalam kriteri pertanyaan yang digagas oleh Nielsen et al (2008).

Penelitian-penelitian sebelunya belum ada upaya untuk mengembangkan kognitif anak melalui pemberiaan pertanyaan LOTS maupun HOTS. Firmanjaya (2019) menggunakan aplikasi Kids Center, Mabruroh (2019) menggunakan metode project based learning, dan Agustin (2019) menggunakan menggunakan pendekatan saintifik namun tanpa disertai dengan penggunaan pertanyaan LOTS maupun HOTS.

Permasalahan yang muncul dari hasil studi terhadap penerapan pendekatan saintifik di PAUD lebih mengacu pada kesulitan dalam melakukan penilaian dan pembuatan rencana pelaksanaan pembelajaran harian bukan pada proses pelaksanaannya (Harmanto \& Kristiana, 2018; Awa, 2019; Meliala, 2017), sehingga peneliti merasa perlu untuk melakukan pemetaan terhadap kemampuan calon guru PAUD dalam mengembangkan konflik kognitif AUD. Calon guru juga telah menjadi objek utama dalam penelitian terdahulu, mengingat kedepannya calon guru akan menjadi guru (Purwoko \& Fitriyah, 2017). Oleh karena itu peneliti teratarik untuk mengetahui bagaimana kemampuan calon guru PAUD menerapkan keterampilan bertanya untuk pengembangan kognitif AUD.

\section{B. Metodologi}

Metode yang digunakan adalah deskriptif kuantitatif mengacu pada analisis konten (Bahçivan, 2017). Partisipan adalah mahasiswa PIAUD UIN Sunan Ampel semester tiga sejumlah 22 mahasiswi yang diambil secara acak dari 68 mahasiswi dan diminta untuk melakukan simulasi pembelajaran dengan sasaran pengembangan kognitif AUD umur 4-6 tahun pada mata kuliah metode pengembangan kognitif. Sebelum simulasi pembelajaran dimulai, mereka sudah mendapatkan informasi bahwa teknik bertanya adalah hal yang penting untuk mengembangkan keterampilan berpikir anak usia dini tanpa mendapatkan bantuan berupa contoh dan mereka menggunakan permendikbud 137 tahun 2014 sebagai pedoman untuk mengetahui tingkat pencapaian perkembangan anak. Mahasiswa juga sudah mengkaji materi tentang Taksonomi Bloom. Selanjutnya peneliti menilai proses pembelajaran yang dilakukan oleh mahasiswa yang bertindak sebagai guru dan mahasiswa yang bertindak sebagai murid.

Langkah-langkah analisis mengacu pada konteks penelitian ini yakni dengan pengumpulan data melalui perekaman video kemudian ditranskripsikan ke dalam bentuk verbatimnya. Proses analisis dilakukan dengan memberikan label bentuk pertanyaan sesuai taksonomi berdasarkan kriteria yang dikembangkan oleh Nielsen, Buckingham, Knoll, Marsh, \& Palen (2008). Selanjutnya dilihat kesinambungan antara pertanyaan yang mengacu pada keterampilan berpikir tingkat dasar (LOTS: Low Order Thinking Skills yakni pertanyaan deskripsi (Q1) dan Pertanyaan Metode (Q2), menuju keterampilan berpikir tingkat tinggi (HOTS: High Order Thinking Skills yaitu Pertanyaan Eksplanasi (Q3), Pertanyaan Rasional (Q4), dan Pertanyaan Preferensi (Q5)). Setelah itu peneliti memberikan penilaian terhadap kesinambungan pertanyaan mulai dari Q1 hingga Q5 sebagai berikut: 


\section{Kartika Metafisika}

Penilaian Keterampilan Bertanya Calon Guru PAUD sebagai Strategi Pengembangan Kognitif Anak Usia Dini

- nilai 1 untuk bentuk pertanyaan yang hanya cenderung mengarah ke pertanyaan deskripsi (Q1).

- nilai 2 untuk bentuk pertanyaan yang sudah terdapat kesinambungan dari pertanyaan deskripsi (Q1) dan Pertanyaan Metode (Q2) namun tidak menuju ke Q3 dan seterusnya.

- nilai 3 adalah untuk bentuk rangkaian pertanyaan yang mengandung unsur HOTS tetapi tidak terlihat kesinambungan pertanyaan dari LOTS ke HOTS.

- nilai 4 untuk rangkaian pertanyaan yang memiliki kesinambungan dari LOTS ke HOTS.

Validasi dilakukan dengan cara diskusi antara peneliti pertama dan peneliti lain dari hasil analisis berdasarkan kriteria yang dikembangkan terhadap partisipan yang sama hingga didapatkan kesepakatan mengenai kriteria pertanyaan yang masuk ke dalam masing-masing taksonomi Pertanyaan (Nielsen et al., 2008) dan kesinambungan pertanyaan guru dari LOTS ke HOTS.

\section{Hasil Dan Pembahasan}

Pengelompokkan hasil penilaian terhadap kriteria pertanyaan yang muncul dalam simulasi ditunjukkan pada Gambar 1 sebagai berikut:

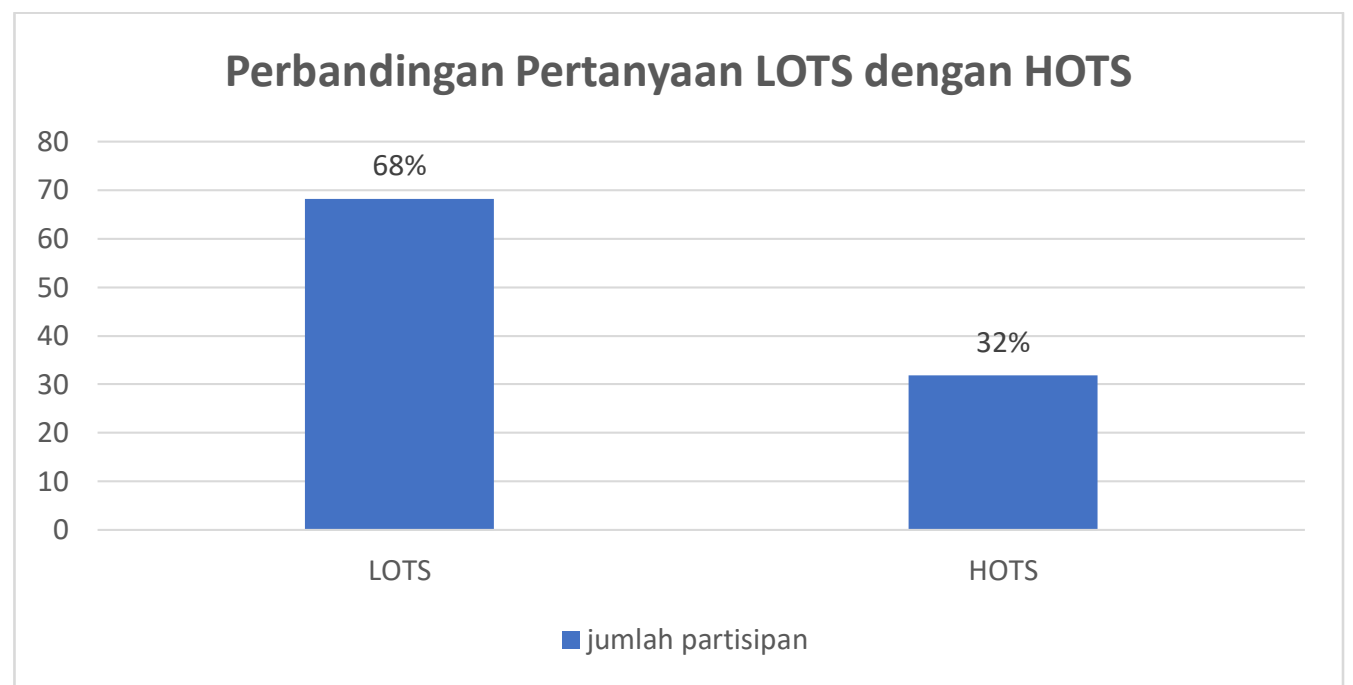

Gambar 1. Perbandingan Jumlah Partisipan yang membuat pertanyaan LOTS dengan HOTS.

Berdasarkan gambar 1 diketahui bahwa jumlah partisipan yang masih memberikan pertanyaan seputar LOTS dua kali lipat lebih banyak dibandingkan dengan partisipan yang mengajukan pertanyaan HOTS.

Berdasarkan jenis-jenis pertanyaan yang muncul dapat diamati dari Tabel 1 sebagai berikut:

Tabel 1. Level Pertanyaan Partisipan

\begin{tabular}{|l|l|l|l|}
\hline $\begin{array}{c}\text { Level } \\
\text { Berpikir }\end{array}$ & Nilai & $\begin{array}{c}\text { Level Pertanyaan } \\
\text { Nielsen yang muncul }\end{array}$ & $\begin{array}{c}\text { Jumlah Partisipan } \\
\text { (orang) }\end{array}$ \\
\hline LOTS & 1 & Q1 & 8 \\
\cline { 2 - 4 } & 2 & Q1 dan Q2 & 7 \\
\hline \multirow{5}{*}{ HOTS } & 3 & Q1 dan Q5 & 1 \\
\cline { 2 - 4 } & 4 & Q1 dan Q3 & 1 \\
\cline { 2 - 4 } & & Q1, Q2 dan Q4 & 1 \\
\cline { 2 - 4 } & Q1, Q2 dan Q3 & 1 \\
\cline { 2 - 4 } & Q1, Q3, dan Q2 & 1 \\
\cline { 2 - 4 } & & Q1, Q3, dan Q4 & 1 \\
\cline { 2 - 4 } & & Q1, Q2, Q3, dan Q4 & 1 \\
\hline
\end{tabular}


Keterangan: LOTS: Low Order Thinking Skills yakni pertanyaan deskripsi (Q1) meliputi

1. apa, siapa, dimana, kapan

2. Definisi

3. Ciri

4. Contoh; dan Pertanyaan Metode (Q2) meliputi perhitungan dan prosedur

HOTS: High Order Thinking Skills yaitu Pertanyaan Eksplanasi (Q3), Pertanyaan Perbandingan (Q4), dan Pertanyaan Preferensi (Q5))

Dari hasil penelitian didapatkan data bahwa yang mendapatkan skor 1 berjumlah 8 orang dan yang mendapatkan skor 2 berjumlah 7 orang. Hal ini dapat menandakan bahwa pertanyaan yang diajukan pada simulasi pembelajaran masih terpaku pada pertanyaan deskriptif (Q1) dan pertanyaan metode (Q2).

Pada partisipan yang mendapatkan skor 1 , bentuk pertanyaan yang muncul hanya seputar melabel tentang benda yang diamati dan tidak dikembangkan menjadi pertanyaan pada level selanjutnya. Sedangkan partisipan yang mendapatkan nilai 2 pertanyaannya berkisar pada pengenalan objek atau masuk ke dalam kategori pertanyaan deskriptif dan pertanyaan metode. Seperti yang ditunjukkan pada pertanyaan berikut:

P4 : “anak-anak tadi berangkat kesekolah naik apa?"Q1

“anak-anak sapa yang tau kendaraan itu ada apa saja ?"Q1

"nah iya betul itu macam-macam kendaraan anak-anak, jadi hari ini kita akan belajar

tentang kendaraan salah satu nya yaitu Bus. Siapa yang pernah naik bus?"Q1

"sapa yang tau bus itu roda nya ada berapa?"(sambil menunjukkan gambar bus)Q2.1

“siapa yang tau tempat berhentinya bus dimana?"Q1

"kita akan bermain memasangkan kartu sesuai warna yang bunda keluarkan ya? "Q2.2

Berdasarkan pertanyaan yang diajukan oleh P4, selain pertanyaan Q1, P4 juga memberikan pertanyaan pada level Q 2.1 yakni pertanyaan yang berhubungan dengan menghitung sedangkan Q2.2 berhubungan dengan prosedur.

Nilai 3 didapatkan partisipan yang sudah memberikan pertanyaan atau penugasan yang melebihi kategori pertanyaan deskripsi (Q1) namun langsung ke pertanyaan preferensi yaitu membuat sesuatu secara bebas (Q5) seperti yang dicontohkan pada pertanyaan yang diajukan oleh P18 berikut:

P18 :

"digambar ini ada yang berwarna merah apa ya ini namanya?" Q1

"selain pohon pisang, dirumah ada pohon apa saja ya?"Q1

"nah sekarang kita mau membuat bunga dari pelepah pisang, ada yang tau apa itu pelepah pisang?" Q1

nah ini adalah pelepah pisang yang nanti anak-anak mencelupkan dulu ke dalam warna setelah itu dicapkan dikertas ya!!'(guru membuat penugasan berupa teknik stempel membentuk gambar bunga menggunakan pelepah pisang) Q5

Pada simulasi yang ditunjukkan oleh P18, pertanyaan-pertanyaan yang diajukan oleh guru tidak berkesinambungan dengan pertanyaan preferensi Q5 yang dikerjakan oleh anak sehingga proses berpikir anak dikhawatirkan tidak melalui tahap penalaran melainkan hanya berkreasi secara bebas.

Sedangkan partisipan yang mendapatkan nilai 4 memberikan pertanyaan dengan melibatkan proses penalaran seperti yang dicontohkan sebagai berikut:

P1: “ada yang tau nggak?? Katak itu biasanya ada di mana yah?” Q1

"wah.. iya...! di belakang rumahnya kiki ada katak nya??" Q1

"iya.. tadi ada yang bilang di darat, terus ada di mana lagi katak itu?" Q1 
"di air, wah.. berarti kalo gitu katak itu bisa ada di 2 tempat yah..? di darat dan di air." Q1

"iyaa, berarti kalo katak itu ada di air katak nya bisa berenang nggak?” Q3

"bisa yahh.. berarti katak itu hidup nya bisa di 2 tem...pat, di mana??” Q1

Meskipun pada pertanyaan ini anak tidak melalui tahap pertanyaan Q2 dan Q3, pertanyaan Q3 yang diajukan bertumpu pada pertanyaan Q1 yang dikembangkan oleh partisipan dapat membangun kepercayaan diri anak untuk menjawab pertanyaan Q3 yang diajukan oleh guru.

Begitu pula pertanyaan yang diajukan oleh P9 sebagai berikut:

P9: “ ini bu guru bawa banyak gambar, mari kita sebutkan fungsinya apa yah teman?” Q1

" dua gambar ini kan sama-sama untuk menulis, lalu bedanya dimanaa ya? (gambar pensil dan bolpoin)" $Q 4$

"kalau ini gambar apa? Terus untuk apa?" (Gambar Penghapus dan stipo cair) Q1

"ini sama-sama untuk menghapus yah teman-teman? Tapi ini berbeda, bedanya dimana yah?" Q4

"kalau teman-teman ke sekolah alat sekolah yang harus dibawa apa aja?"Q1

teman-teman...., ini kan ada banyak gambar yang dibawa bu guru, ayo siapa yang bantu bu guru untuk milih mana alat sekolah yang harus dibawa? Yang bukan alat sekolah di taruh disini ya! $Q 4$

P9 sudah mampu memberikan pertanyaan yang tidak hanya berada pada ranah Q1 tetapi juga dapat menggali kemampuan abstraksi siswa dalam melihat detail dengan membedakan ciri dan fungsi benda. Berdasarkan pemikiran Blank, pertanyaan ini sudah melibatkan perspektif analisis (tingkat abstraksi bahasa Blank level 2) diluar perspektif mencocokkan (tingkat abstraksi bahasa Blank level 1) dan juga setara dengan pertanyaan HOTS yakni ranah analisis taksonomi Bloom.

P10 dan P12 merangkai pertanyaan agar anak dapat memberikan eksplanasi (Q3) disertai dengan menerapkan metode menghitung $(\mathrm{Q} 2)$. Begitu pula pertanyaan yang diajukan oleh P10 dan P12 yang dapat mengembangkan penalaran anak sebagai berikut:

P10 : "hayo sebutkan bagian-bagian yang ada pada jagung!” Q1

"sekarang bunda beri tugas ya, jadi kalian harus menjumlahkan berapa banyak

jagung yang ada di gambar, bisa anak-anak?” Q2

"(guru membuat eksperimen tentang jagung menari dengan cara memasukkan jagung ke dalam air kemudian dimasukkan soda kue dan cuka sehingga terjadi reaksi menghasilkan gas) anak-anak kalian tau tidak kok bisa jagungnya menari-nari seperti itu didalam gelas? jadi ada campuran bahan soda kue dan cuka yang bisa membentuk gas yang menyebabkan jagungnya bisa bergerak keatas dan kebawah. Jadi paham anak-anak?" Q3

P12: “Biasanya yang mengendarai pesawat itu namanya apa ya?” $Q 1$

"Kira-kira kalau pesawat terbang itu punya roda apa tidak ya?" Q3

"kalau ada, siapa yang tau berapa jumlah roda pesawat terbang?” Q2

\section{Kesimpulan}

Melihat pola pada pertanyaan yang muncul dalam penelitian, diketahui bahwa sebanyak 68\% partisipan masih mengemukakan pertanyaan dalam bentuk Low Order Thinking Skills (LOTS) dan 32\% sudah mempraktekkan pertanyaan untuk mengembangkan High Order Thinking Skills (HOTS). Semua partisipan memulai pertanyaan dari pertanyaan deskripsi yakni tentang apa, siapa, dimana, dan kapan. Pertanyaan LOTS yang muncul paling banyak seputar pertanyaan deskripsi mengenai apa, siapa, dimana, dan kapan disertai berhitung jumlah objek.

Child Education Journal. Volume 1, No. 2 December 2019, 88-95 
Pada pertanyaan HOTS, pertanyaan yang ideal adalah pertanyaan yang melalui proses penalaran (Q3) atau bagaimana anak bisa mengamati secara detail objek yang dipelajari melalui proses membedakan (Q4).

Pada kasus ini, pertanyaan HOTS yang muncul ada yang melalui proses penalaran dan ada yang tidak melalui proses penalaran. Pada pertanyaan HOTS yang muncul tanpa proses penalaran, partisipan langsung mengarah ke pertanyaan preferensi sehingga dikhawatirkan tidak ada kesinambungan informasi yang dirangkai oleh anak dan anak mengalami kesulitan dalam menjawab pertanyaan preferensi tanpa disertai contoh.

Penelitian selanjutnya dapat dilakukan dengan menggunakan kriteria pada studi untuk memetakan bentuk pertanyaan yang digunakan oleh guru PAUD di Indonesia. Selain itu kriteria dapat digunakan sebagai pedoman bagi guru untuk mendesain bentuk pertanyaan dalam pembelajaran sebagai strategi stimulasi HOTS AUD.

\section{Daftar Pustaka}

Agustin, Nurul. (2019). Pengaruh Pendekatan Saintifik Terhadap Keterampilan Berpikir Kritis Siswa Subtema Keberagaman Makhluk Hidup Di Lingkunganku Kelas IV Sekolah Dasar. Child Education Journal, Volume 1 Nomor 1, https://doi.org/10.33086/cej.v1i1.912.

Akkaya, N., \& Demirel, M. V. (2012). Teacher Candidates' Use of Questioning Skills in During-Reading and Post-Reading Strategies. Procedia-Social and Behavioral Sciences, 46, 4301-4305.

Aubrey, C., Ghent, K., \& Kanira, E. (2012). Enhancing thinking skills in early childhood. International Journal of Early Years Education, 20(4), 332-348.

Awa, M. (2019). Meningkatkan Kemampuan Guru Taman Kanak-kanak dalam Menyusun RPPH melalui Kegiatan Supervisi Akademik dan Pendampingan di TK Binaan Tahun 2018. Serambi PTK, 6(2), 55-63.

Bahçivan, E. (2017). Implementing Microteaching Lesson Study with a Group of Preservice Science Teachers: An Encouraging Attempt of Action Research. International Online Journal of Educational Sciences, 9(3).

Danur, D. T., \& Nurhafizah, N. (2019). Profesionalisme Guru Paud Dalam Mengembangkan Kurikulum Tingkat Satuan Pendidikan Tk Berbasis Kurikulum 2013. Jurnal Pendidikan Tambusai, 3(2), 715-721.

Firmanjaya, Alan. (2019). Strategi Pemanfaatan Aplikasi Kids Center untuk Mengembangkan Kreatifitas Anak Kelompok A di Lingkungan Keluarga. Child Education Journal, Volume 1 Nomor 1, https://doi.org/10.33086/cej.v1i1.1018

Harmanto, B., \& Kristiana, D. (2018). Memudahkan Pelaporan Perkembangan Anak Tk Melalui Program Aplikasi. JURNAL AUDI: Jurnal Ilmiah Kajian Ilmu Anak Dan Media Informasi PAUD, 2(2).

Hartatik, S. \& Fitriyah, F.K. (2017). Identifikasi Kecemasan Matematika Pada Mahasiswa Program Studi Pendidikan Guru Sekolah Dasar. Jurnal Bimbingan Konseling Indonesia. 2(2). 31 - 33, DOI: http://dx.doi.org/10.26737/jbki.v2i2.253.

Katz, L. G. (2010). STEM in the early years. Early Childhood Research and Practice, Vol. 12, pp. 11-19.

Mabruroh, Milda. (2019). Pengaruh Model Pembelajaran Project Based Learning Pada Mata Pelajaran IPA Terhadap Kemampuan Berpikir Kritis Siswa Kelas VI SD Negeri Margorejo VI Surabaya. Child Education Journal, Volume 1 Nomor 1, https://doi.org/10.33086/cej.v1i1.879 
Meliala, N. R. M. B. S. (2017). Analisis Kesulitan Guru Paud Dalam Pelaksanaan Kurikulum 2013 Di Kecamatan Kabanjahe Kabupaten Karo Ta 2016/2017. UNIMED.

Natalia, E. D., Sofia, A., \& others. (2016). Persepsi Guru PAUD Terhadap Kompetensi Pedagogik. Jurnal Pendidikan Anak, 2(2).

Nielsen, R. D., Buckingham, J., Knoll, G., Marsh, B., \& Palen, L. (2008). A taxonomy of questions for question generation. Proceedings of the Workshop on the Question Generation Shared Task and Evaluation Challenge.

Purwoko, Budi., \& Fitriyah, F. K. (2017). Narcissism and Aggression in Counselor Candidates: A Challenge for Counselor Education in Indonesia. Proceedings of the 9th International Conference for Science Educators and Teachers (ICSET 2017, https://doi.org/10.2991/icset-17.2017.38.

Storey, S. O. (2004). Teacher questioning to improve early childhood reasoning. The University of Arizona.

Ting, T. C. (2007). Policy developments in pre-school education in Singapore: A focus on the key reforms of kindergarten education. International Journal of Child Care and Education Policy, 1(1), 35.

Trundle, K. C. (2010). Teaching science during the early childhood years. Best Practices in Science Education.

Welsh, J. A., Nix, R. L., Blair, C., Bierman, K. L., \& Nelson, K. E. (2010). The development of cognitive skills and gains in academic school readiness for children from low-income families. Journal of Educational Psychology, 102(1), 43.

Westby, C. (2017). Marion Blank's Levels of Language Abstraction. Word of Mouth, 29(1), 1215. 